\title{
Antihyperglycemic Effects of Fermented and Nonfermented Mung Bean Extracts on Alloxan-Induced-Diabetic Mice
}

\author{
Swee Keong Yeap, ${ }^{1}$ Norlaily Mohd Ali, ${ }^{2}$ Hamidah Mohd Yusof, ${ }^{2}$ Noorjahan Banu Alitheen, ${ }^{2}$ \\ Boon Kee Beh, ${ }^{3}$ Wan Yong Ho, ${ }^{2}$ Soo Peng Koh, ${ }^{4}$ and Kamariah Long ${ }^{4}$
}

${ }^{1}$ Institute of Bioscience, Universiti Putra Malaysia, Selangor, 43400 Serdang, Malaysia

${ }^{2}$ Department of Cell and Molecular Biology, Faculty of Biotechnology and Biomolecular Science, Universiti Putra Malaysia, Selangor, 43400 Serdang, Malaysia

${ }^{3}$ Department of Bioprocess Technology, Faculty of Biotechnology and Biomolecular Science, Universiti Putra Malaysia, Selangor, 43400 Serdang, Malaysia

${ }^{4}$ Biotechnology Research Centre, Malaysian Agricultural Research and Development Institute (MARDI), Selangor, 43400 Serdang, Malaysia

Correspondence should be addressed to Kamariah Long, amai@mardi.gov.my

Received 14 July 2012; Revised 30 July 2012; Accepted 26 August 2012

Academic Editor: Elvira Gonzalez De Mejia

Copyright ( $\odot 2012$ Swee Keong Yeap et al. This is an open access article distributed under the Creative Commons Attribution License, which permits unrestricted use, distribution, and reproduction in any medium, provided the original work is properly cited.

\begin{abstract}
Mung bean was reported as a potential antidiabetic agent while fermented food has been proposed as one of the major contributors that can reduce the risk of diabetes in Asian populations. In this study, we have compared the normoglycemic effect, glucose-induced hyperglycemic effect, and alloxan-induced hyperglycemic effect of fermented and nonfermented mung bean extracts. Our results showed that fermented mung bean extracts did not induce hypoglycemic effect on normal mice but significantly reduced the blood sugar levels of glucose- and alloxan-induced hyperglycemic mice. The serum levels of cholesterol, triglyceride (TG), and low-density lipoprotein (LDL) were also lowered while insulin secretion and antioxidant level as measured by malonaldehyde (MDA) assays were significantly improved in the plasma of the fermented mung bean-treated group in alloxaninduced hyperglycemic mouse. These results indicated that fermentation using Mardi Rhizopus sp. strain 5351 inoculums could enhance the antihyperglycemic and the antioxidant effects of mung bean in alloxan-treated mice. The improvement in the antihyperglycemic effect may also be contributed by the increased content of GABA and the free amino acid that are present in the fermented mung bean extracts.
\end{abstract}

\section{Introduction}

Diabetes mellitus is a common endocrine disease that is characterized by chronic hyperglycemia and insulin deficiency or resistance which are associated with other complications such as macroangiopathy and microangiopathy. Moreover, studies have also recorded that hyperglycemia can eventually induce the production of reactive oxygen species (ROS) and nitric oxide (NO) in the long run [1], increase $\beta$ cell apoptosis, decrease $\beta$ cell mass, and cause insulin deficiency and resistance [2]. To date, the treatment for diabetes including insulin, metformin, and sulfonylureas was found to cause various side effects especially the development of resistance after a certain period of time [3]. Thus, efforts to search for alternative and novel therapies to manage diabetes are still receiving great attention.

Personalized nutritional management and physical activity have been recommended to replace the American Diabetes Association diet to achieve better glycemic control in diabetic patients [4]. Besides, complementary and alternative medicine in the form of plant-based food and spices that are commonly used in traditional medicine to treat diabetes have also been recommend as better oral agents. For example, Momordica charantia (bitter melon) is a traditional antidiabetic remedy that has been identified as a potential hypoglycemic agent in streptozocin/alloxan-induced diabetic 
and type II diabetic subjects [5]. Other than herbs, whole grains and cereals that serve as the source of energy in Asian food have also been suggested as potential antidiabetic food due to their low-glycemic indices $[6,7]$. The glycemic index of a food is defined as an effect on postprandial glucose in comparison to the reference food. Low-glycemic index foods have been proven to improve glycemic control of insulin and noninsulin-dependent diabetes mellitus [8]. Mung bean (Vigna radiata $\mathrm{L}$.) is a food that is traditionally used to reduce fever and used for detoxification. Among all types of seeds, mung bean has been recommended as an alternative food for diabetic patients due to its high-fiber content and lowglycemic index [6]. Yao et al. [9] had reported that ethanolic extract of mung bean was able to reduce blood glucose, total cholesterol, and TG levels while enhancing the glucose tolerance and insulin sensitivity in type II diabetic mice.

Fermentation is a common food processing method traditionally practiced in the East and Southeast Asian regions to improve the food colour quality, flavour, or even the nutrient content. Alterations made by microflora during the fermentation process may help to release the active ingredients that are beneficial to human health. Fermented soybean, for example, was found to have better antidiabetic effect due to attenuation of the structures and contents of isoflavonoids and smaller bioactive peptides [2]. Although the antihyperglycemic effect of mung bean has been reported, the potential of fermentation in improving the antihyperglycemic and the antioxidant effect of mung bean is still unknown. Thus, this study compared the effects of fermented and nonfermented mung bean extracts on normoglycemic, glucose-induced hyperglycemic and alloxaninduced hyperglycemic mice. The serum antioxidant levels of extracts treated alloxan-induced hyperglycemic mice were also evaluated in this study.

\section{Materials and Methods}

2.1. Chemicals. Alloxan, glucose, Folin-Ciocalteu reagent, ascorbic acid, Gallic acid, and GSH assay kit were purchased from Sigma-Aldrich (USA). Griess reagent was obtained from Invitrogen (USA). Momordica charantia was purchased from CCM Pharmaceutical (Malaysia) as positive control in this study. Rhizopus sp. strain 5351 inoculums were obtained from the culture collection center of the Malaysian Agricultural Research and Development Institute (MARDI).

\subsection{Preparation of Fermented and Nonfermented Mung Bean} Extracts. Seeds of mung bean (Vigna radiate) were subjected to solid-state fermentation before extraction. The beans were inoculated with Rhizopus sp. strain 5351 inoculums, for $48 \mathrm{~h}$ at $30^{\circ} \mathrm{C}$. Then, the fermented bean was dried and ground into powder followed by water extraction in the ratio of $1 \mathrm{~g}$ of fermented seeds in $20 \mathrm{~mL}$ of deionised water $\left(25^{\circ} \mathrm{C}\right)$ for 30 minutes. The mixture was then centrifuged and the supernantant was freeze-dried at an operating temperature of $-50^{\circ} \mathrm{C}$ to obtain a final yield of $25 \%(w / w)$. UPLC analysis was performed on a Acquity UPLC system (Waters Corp, USA) coupled with Acquity UPLC AccQ Tag Ultra Column
$(2.1 \times 100 \mathrm{~mm}, 1.7 \mu \mathrm{m})$ and $\mathrm{PDA}$ detector at $55^{\circ} \mathrm{C}$ to analyse GABA and amino acid concentrations. GABA and amino acids were separated using a gradient mobile phase consisting of A: AccQ Tag Ultra Eluent A and B: AccQ Tag Ultra Eluent $B$ with the following gradient conditions: $0-0.54 \mathrm{~min}$, $0.1-9.1 \% \mathrm{~B} ; 5.74-7.74 \mathrm{~min}, 9.1 \%-21.2 \% \mathrm{~B}$; and finally, reconditioning the column with $0.1 \% \mathrm{~B}$ with isocratic flow for $2.1 \mathrm{~min}$ after washing column with $59.6 \% \mathrm{~B}$ for $0.30 \mathrm{~min}$. One $\mu \mathrm{L}$ of all samples and standards were injected at a flow rate of $0.7 \mathrm{~mL} / \mathrm{min}$. The data were then analyzed using the Waters Empower 2 software. From the analysis, every $100 \mathrm{~g}$ of the nonfermented mung bean extract contained $0.016 \pm$ $0.001 \mathrm{~g}$ of GABA and $0.256 \mathrm{~g}$ of total amino acids. In contrast, the concentration of GABA in the fermented mung bean extract increased by 7.6 -fold to $0.122 \pm 0.009 \mathrm{~g} / 100 \mathrm{~g}$ of dried powder while the amount of amino acids increased by 13 fold to $3.326 \mathrm{~g} / 100 \mathrm{~g}$ dried powder.

2.3. Experimental Design. The experiments were evaluated on normoglycemic, glucose-induced hyperglycemic, and alloxan-induced diabetic mice. The mice were subjected to $18 \mathrm{~h}$ of fasting before each test was carried out.

$\mathrm{Balb} / \mathrm{c}$ mice ( 8 weeks old, 18-22 g) were purchased from the Animal House in the Institute of Bioscience, University Putra Malaysia. Standard laboratory pellet diet and water were made available ad libitum throughout the experimental period at $22^{\circ} \mathrm{C}$ of dark-light cycle. This study was approved by the Animal Care and Use Committee of University Putra Malaysia. Mice were randomly assigned into their respective groups for normoglycemic, glucose-induced hyperglycemic, and alloxan-induced hyperglycemic studies as listed below. Blood glucose was collected from all experimental mice for analysis after $18 \mathrm{~h}$ of fasting [10].

2.3.1. Normoglycemic Mice. Mice were randomly assigned into five different groups $(n=8)$. Group I: normal control mice without any treatment; Group II: $M$. charantia extract $(200 \mathrm{mg} / \mathrm{kg})$; Group III: nonfermented mung bean extract $(1000 \mathrm{mg} / \mathrm{kg})$; Group IV and V: fermented mung bean extract $(200 \mathrm{mg} / \mathrm{kg}$ and $1000 \mathrm{mg} / \mathrm{kg}$, resp.). After 18 hours of fasting, blood glucose was determined $(0 \mathrm{~min})$ before oral administration of distilled water or the respective extracts $(0.3 \mathrm{~mL} / \mathrm{mice})$ was given to each mouse. Monitoring of blood glucose level was continued at 30,60,120, and $240 \mathrm{~min}$ after the administration of treatment or distilled water [10].

2.3.2. Glucose-Induced Hyperglycemic Mice. Mice were randomly assigned into five different groups $(n=8)$ as listed above. After $18 \mathrm{~h}$ of fasting, blood glucose level was determined at $0 \mathrm{~min}$. Then, oral feeding of distilled water or the respective extract was given simultaneously with $1 \mathrm{~g} / \mathrm{kg}$ $(0.3 \mathrm{~mL})$ of glucose solution to each group. Monitoring of blood glucose level was continued at 30, 60, 120, and $240 \mathrm{~min}$ after the oral administration [10].

2.3.3. Alloxan-Induced Diabetic Mice. The mice were randomly assigned into six different groups $(n=8)$. Group 1 was the normal control mice that received distilled 
water as placebo while groups 2-6 were diabetic mice. Diabetes was induced using intraperitoneal injection of alloxan $(100 \mathrm{mg} / \mathrm{kg}, 0.1 \mathrm{~mL})$. The hyperglycemic mice were maintained on $5 \%$ glucose solution for the next $24 \mathrm{~h}$ to prevent hypoglycemia and monitored for 3 days to ensure constant blood glucose levels before they were subjected to 18 hours of fasting. After the fasting period, blood glucose was determined at $0 \mathrm{~min}$, followed by oral feeding with distilled water (group 1 and 2) or the respective treatment. Group 3 received M. charantia extract $(200 \mathrm{mg} / \mathrm{kg})$; Group 4 received nonfermented mung bean extract $(1000 \mathrm{mg} / \mathrm{kg})$; Group 5 and 6 received fermented mung bean extract $(200 \mathrm{mg} / \mathrm{kg}$ and $1000 \mathrm{mg} / \mathrm{kg}$, resp.). In addition, all the mice were also fed with glucose solution once $(1 \mathrm{~g} / \mathrm{kg}, 0.3 \mathrm{~mL}$, p.o.). Monitoring of blood glucose level was continued at 30,60,120, and $240 \mathrm{~min}$ after administration. Treatments with distilled water and the extracts were continued for a total of 10 days. On the last day of treatment, all mice were fasted for $18 \mathrm{~h}$ before being anesthetized with ether and sacrificed by cervical dislocation. Blood was collected to obtain serum for determination of glucose, total cholesterol (Biovision, USA), triglyceride (TG) (Biovision, USA), low-density lipoprotein (LDL) (Biovision, USA), high-density lipoprotein (HDL) (Biovision, USA), and insulin (Mercodia, Sweden) levels. Quantification was carried out according to the manufacturer's protocol. The antioxidant level of serum was evaluated by detecting the level of malondiadehyde (MDA) as described previously [11] while serum nitric oxide level was determined using the Griess method (Invitrogen, USA).

2.4. Statistical Analysis. The results for blood glucose level, serum biochemical profiles, and antioxidant level were presented as mean \pm S.D. One way analysis of variance (ANOVA) followed by Duncan test was used in this study with $P$ values $<0.05$ being considered as significant.

\section{Results}

3.1. Normoglycemic and Glucose-Induced Hyperglycemic Effect. Overall, fermented mung bean, nonfermented mung bean, and $M$. charantia extracts did not produce any hypoglycemic effect but caused slight hyperglycemic effect within 2 hours of oral feeding in normal mice (Figure 1(a)).

However, for the glucose-induced hyperglycemic mice, the animals from all groups were found to develop high blood glucose levels at the first 30 minutes after oral administration (Figure 1(b)). However, treatment with $1000 \mathrm{mg} / \mathrm{kg}$ body weight of fermented and nonfermented mung bean extracts could significantly reduce the elevated blood glucose level in comparison to the normal control group. Although significant effect was also shown by the M. charantia extract treatment but the effect was comparatively weaker than in the previous groups. On the other hand, low concentrations of the fermented mung bean extract did not show any significant difference in antihyperglycemic effect when compared to the normal control.

3.2. Alloxan-Induced Hyperglycemic Effect. Significant changes of body weights were observed in the untreated normal mice. For all the diabetic mice, changes of body weights were not significant (Figure 2). Treatments on day $1-5$ were based on $22 \mathrm{~g} /$ mice while from day 6 to 10 were based on $24 \mathrm{~g} /$ mice. Generally, diabetic mice (Groups 2 to 6) gained less weight than normal mice (Group 1) during the treatment period (Figure 2). Nonfermented mung bean showed a hyperglycemic effect similar to the untreated diabetic mice in group 2. M. charantia and fermented mung bean extracts $(200 \mathrm{mg} / \mathrm{kg}$ body weight) on the other hand were able to prevent drastic increases in blood sugar when compared to the untreated diabetic mice. Among all treatment groups, high concentration of fermented mung bean extract $(1000 \mathrm{mg} / \mathrm{kg}$ body weight) was able to reduce blood sugar level most significantly throughout the period of monitoring (30 min to 2 hours after feeding) (Figure 1(c)).

The alloxan-induced diabetic mice were monitored continuously in the following 10 days with continued treatment for groups 3 to 6 . Untreated mice in group 2 maintained a high blood glucose level in comparison to mice in the other groups. The blood sugar levels of $M$. charantia, nonfermented mung bean, and low concentration of fermented mung bean $(200 \mathrm{mg} / \mathrm{kg}$ body weight $)$ extracts treatment groups were found to be reduced slightly at day 10 while a high concentration of fermented mung bean extract at $1000 \mathrm{mg} / \mathrm{kg}$ body weight was able to reduce blood sugar levels even at day 5 after administration (Figure 1(d)).

The serum lipid profile and the insulin level of the alloxan-induced hyperglycemic mice after 10 days of treatment were assessed. Untreated diabetic mice in group 2 showed significantly higher levels of total cholesterol and TG but lower levels of HDL and insulin. In contrast, a high concentration of fermented mung bean extract $(1000 \mathrm{mg} / \mathrm{kg}$ body weight) showed lower levels of total cholesterol and TG but higher levels of insulin and HDL in comparison to the nonfermented mung bean extract (Table 1). Similar to the effects on serum lipid profile and insulin levels, untreated diabetic mice in group 2 exhibited significantly higher MDA and NO levels. Both M. charantia and fermented mung bean extracts were able to restore the antioxidant level more effectively than the nonfermented mung bean extract. Besides, we also observed that the antihyperglycemic effect of the fermented mung bean extract was dosage dependent whereby a higher concentration of fermented mung bean (comparing between Group 5 and Group 6) exhibited better antioxidant activity with lower NO level (Table 1).

\section{Discussion}

Previously, M. charantia [12] and mung bean [9] have been reported as potential antidiabetic agents. Low-glycemicindex mung bean was able to reduce plasma lipid level, epidilymal adipocyte volume and plasma insulin [6-8]. Thus, mung bean has been recommended as a food of choice for diabetic patients. However, it is still uncertain whether fermentation could enhance the antidiabetic effect of mung bean. In this study, we have compared the antihyperglycemic effects of fermented and nonfermented mung bean extracts in normoglycemic, glucose-induced hyperglycemic, and alloxan-induced hyperglycemic mice. Normal fasting blood 


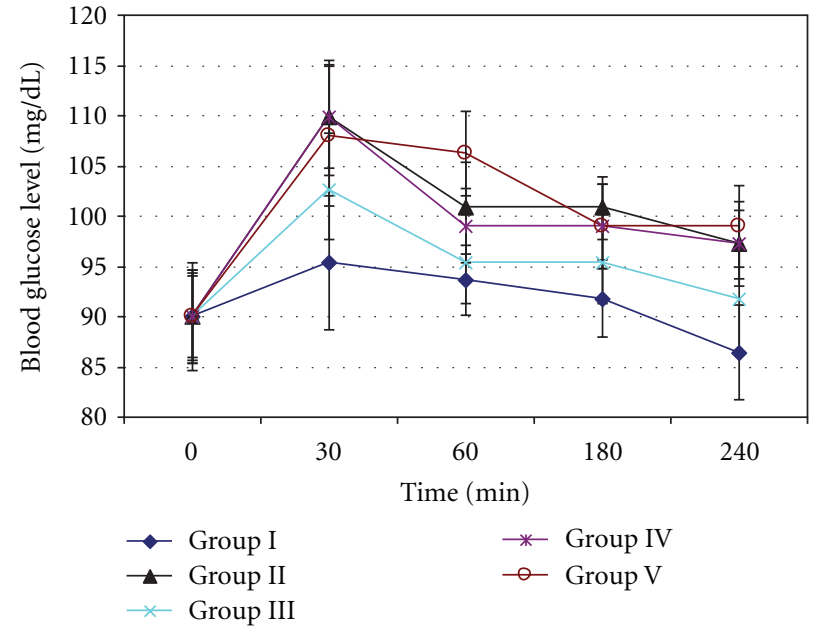

(a)

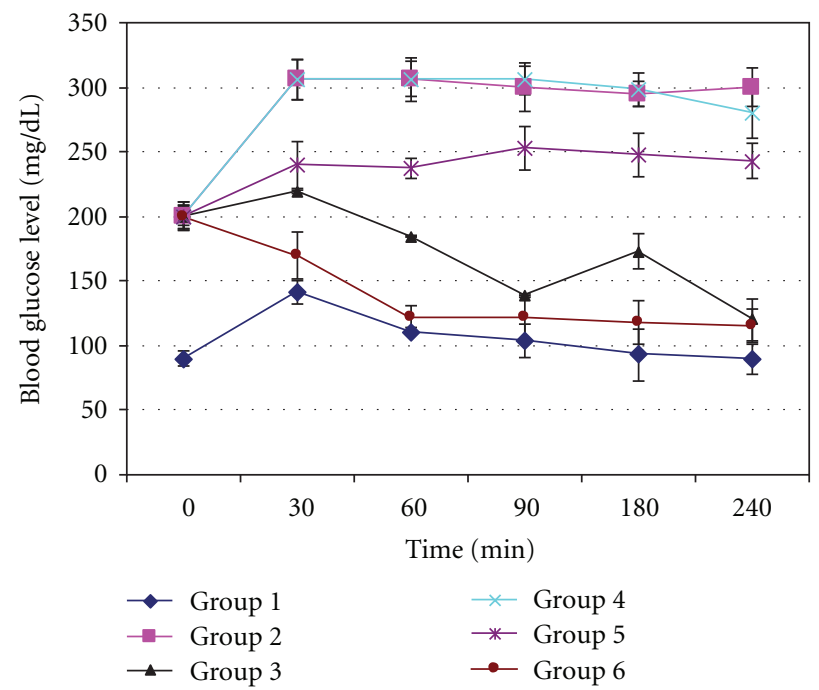

(c)

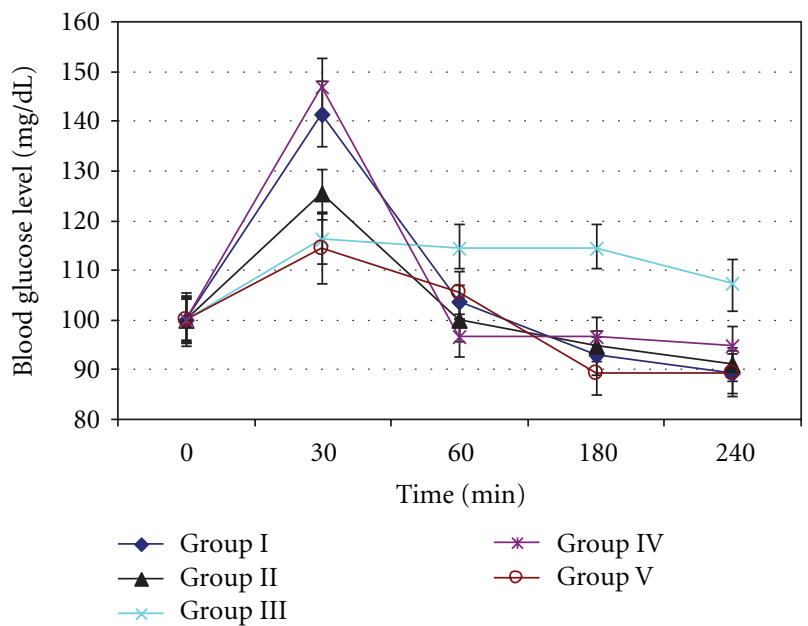

(b)

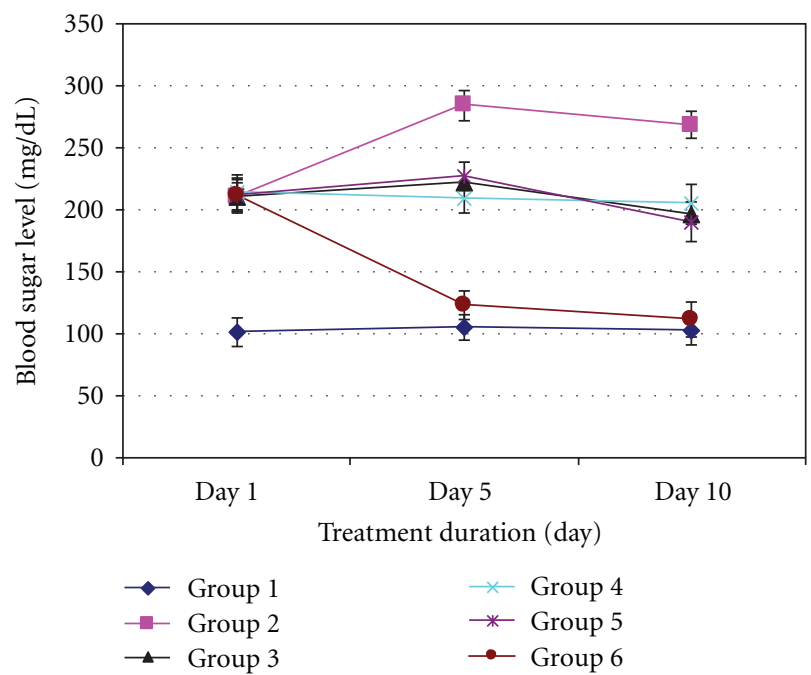

(d)

Figure 1: Effect of fermented, nonfermented mung bean and M. charantia extracts on (a) normoglycemic mice, (b) glucose-induced hyperglycemic mice, (c) alloxan-induced hyperglycemic mice, and (d) alloxan-induced hyperglycemic mice after 10 days of treatment. Grouping for (a) and (b) are Group I: normal control; Group II: M. charantia extracts ( $200 \mathrm{mg} / \mathrm{kg}$ ); Group III: normal + nonfermented mung bean extracts ( $1000 \mathrm{mg} / \mathrm{kg}$ ); Group IV: fermented mung bean extracts (200 mg/kg); Group V: fermented mung bean extracts (1000 mg/kg) while grouping for (c) and (d) are Group 1: normal control; Group 2: diabetic control; Group 3: diabetic + M. charantia extracts (200 mg/kg); Group 4: diabetic + nonfermented mung bean extracts (1000 mg/kg); Group 5: diabetic + fermented mung bean extracts (200 mg/kg); Group 6: diabetic + fermented mung bean extracts $(1000 \mathrm{mg} / \mathrm{kg})$.

glucose for mice is around $90 \mathrm{mg} / \mathrm{dL}(\sim 5 \mathrm{mmol} / \mathrm{L})$. Animals having fasting blood glucose levels more than $200 \mathrm{mg} / \mathrm{dL}$ $(\sim 11 \mathrm{mmol} / \mathrm{L})$ were considered as diabetic. In this study, changes of fasting blood glucose of normaglycaemic and glucose-induced hyperglycaemic mice which were $20 \%$ lower than those of the untreated normal control were considered as hypoglycaemia [13]. All the extract-treated mice in the normoglycemic study showed slight increases in blood sugar without indication of hypoglycemic effect. This outcome may be contributed by the primary metabolites that are present in the water extract, or more specifically by the carbohydrates in this context. However, in both glucoseand alloxan-induced hyperglycemic mice, M. charantia, fermented and non-fermented mung bean extracts were able to reduce oral glucose tolerance to prevent drastic glucose increase in the blood. These results suggested the possibility of using fermented and nonfermented mung bean extracts for regulating blood sugar via their antihyperglycemic effects, which could enhance glucose adsorption in the gut [14]. Continued administration of the extracts for 10 days had also been associated with blood sugar reduction (Figure 1(d)). Fermented mung bean extract at $1000 \mathrm{mg} / \mathrm{kg}$ body weight showed the best reductions of blood sugar levels of diabetic mice at day 5. M. charantia, nonfermented mung bean, and low concentration of fermented mung bean extracts showed similar trends of reduction at day 10 . The findings from 
TABLE 1: Effect of fermented and nonfermented mung bean and M. charantia extracts on serum total cholesterol, TG, LDL, HDL, insulin, MDA, and NO levels of alloxan-induced diabetic mice.

\begin{tabular}{|c|c|c|c|c|c|c|c|}
\hline Treatment & $\begin{array}{c}\text { Total cholesterol } \\
(\mathrm{mmol} / \mathrm{L})\end{array}$ & $\begin{array}{l}\text { Triglyceride } \\
(\mathrm{mmol} / \mathrm{L})\end{array}$ & $\begin{array}{c}\mathrm{LDL} \\
(\mathrm{mmol} / \mathrm{L})\end{array}$ & $\begin{array}{c}\mathrm{HDL} \\
(\mathrm{mmol} / \mathrm{L})\end{array}$ & $\begin{array}{l}\text { Insulin } \\
(\mu \mathrm{g} / \mathrm{L})\end{array}$ & $\begin{array}{c}\text { MDA } \\
(\mathrm{nmol} / \mathrm{g} \text { of protein) }\end{array}$ & $\begin{array}{c}\mathrm{NO} \\
(\mu \mathrm{M} / \mathrm{mg} \text { protein }) \\
\end{array}$ \\
\hline $\begin{array}{l}\text { Group } 1 \\
(n=8)\end{array}$ & $3.70 \pm 0.07^{*}$ & $3.74 \pm 0.04^{*}$ & $0.23 \pm 0.04^{*}$ & $2.60 \pm 0.14$ & $73.34 \pm 2.34$ & $8.72 \pm 0.33^{*}$ & $4.13 \pm 0.37^{*}$ \\
\hline $\begin{array}{l}\text { Group } 2 \\
(n=8)\end{array}$ & $4.36 \pm 0.11$ & $4.46 \pm 0.10$ & $0.40 \pm 0.08$ & $2.49 \pm 0.28$ & $31.24 \pm 3.71$ & $21.86 \pm 1.12$ & $8.42 \pm 0.53$ \\
\hline $\begin{array}{l}\text { Group } 3 \\
(n=8)\end{array}$ & $4.11 \pm 0.18$ & $3.74 \pm 0.37^{*}$ & $0.25 \pm 0.06^{*}$ & $2.89 \pm 0.39$ & $54.52 \pm 4.29$ & $14.66 \pm 0.77^{*}$ & $5.78 \pm 0.61^{*}$ \\
\hline $\begin{array}{l}\text { Group } 4 \\
(n=8)\end{array}$ & $4.12 \pm 0.05$ & $3.96 \pm 0.51^{*}$ & $0.27 \pm 0.04^{*}$ & $2.70 \pm 0.03$ & $51.33 \pm 2.74$ & $17.32 \pm 0.69^{*}$ & $6.11 \pm 0.74^{*}$ \\
\hline $\begin{array}{l}\text { Group } 5 \\
(n=8)\end{array}$ & $4.09 \pm 0.01$ & $3.83 \pm 0.11^{*}$ & $0.29 \pm 0.01^{*}$ & $2.76 \pm 0.07$ & $42.31 \pm 3.32$ & $19.93 \pm 1.11^{*}$ & $6.47 \pm 0.33^{*}$ \\
\hline $\begin{array}{l}\text { Group } 6 \\
(n=8)\end{array}$ & $3.80 \pm 0.30^{*}$ & $2.62 \pm 0.10^{*}$ & $0.29 \pm 0.05^{*}$ & $2.82 \pm 0.13$ & $61.18 \pm 4.51$ & $12.69 \pm 0.82 *$ & $5.34 \pm 0.52 *$ \\
\hline
\end{tabular}

Group 1: normal control; Group 2: diabetic control; Group 3: diabetic + M. charantia extracts ( $200 \mathrm{mg} / \mathrm{kg})$; Group 4: diabetic + nonfermented mung bean extracts (1000 mg/kg); Group 5: diabetic + fermented mung bean extracts ( $200 \mathrm{mg} / \mathrm{kg})$; Group 6: diabetic + fermented mung bean extracts (1000 mg/kg).

${ }^{*} P>0.05$ versus group 2 (diabetic control).

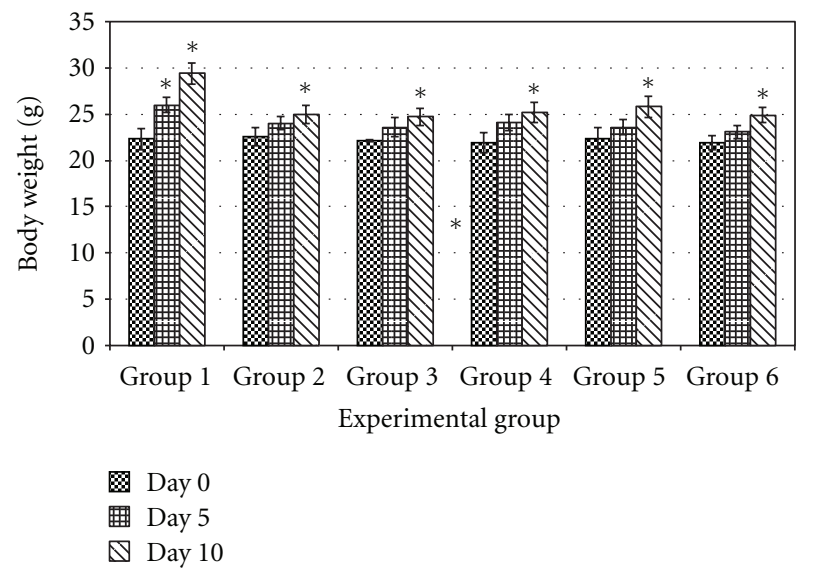

Figure 2: Effect of fermented, nonfermented mung bean and $M$. charantia extracts on body weight changes of alloxan-induced hyperglycemic mice after 10 days of treatment. ${ }^{*} P>0.05$ versus day 0 .

this study were in good agreement with a previous report on the assistance of M. charantia in the regulation of blood sugar via improved insulin sensitivity [12] and recovery of $\beta$-cells in the pancreas after 12 days of treatment [4]. In this study, fermented mung bean $(200 \mathrm{mg} / \mathrm{kg}$ body weight $)$ and non-fermented mung bean exhibited a trend of blood sugar regulation similar to that of $M$. charantia extract. Therefore, fermented and nonfermented mung bean extracts could also possibly regulate blood sugar level by enhancing the sensitivity of insulin and by the regeneration of $\beta$-cells in the pancreas.

Clinical studies had reported that low-glycemic-index diet contributed small effects on the control of postprandial hyperglycemia in diabetic patients [15]. Thus, the improved antidiabetic effect due to fermented mung bean may be contributed by the enhancement of phytochemicals during the fermentation process. Advances in the effectiveness for controlling glucose metabolism through fermentation were also reported for soy bean $[2,16]$. This effect was related to the increase of isoflavonoid aglycones during the fermentation process [2]. Solid state fermentation was predicted to improve the antidiabetic effect of mung bean via enrichment of antioxidants and phytochemicals [17]. In this study, we have found that enhanced blood sugar regulation by a high concentration of fermented mung bean may be contributed by the enriched GABA content ( 7.6 fold) in the extract as compared to the nonfermented mung bean. The regenerative effect of GABA on islet $\beta$-cell via activation of PI3-K/Akt-dependent growth and survival pathways had been reported by Soltani et al. [18] and Tian et al. [19] on both type I and type II diabetic mice. Besides GABA, free amino acids (13 fold increase in fermented mung bean) had also been reported as an effective oral supplement for diabetic patients [20]. Among the tested free amino acids, lysine which recorded a marked increase in the fermented mung bean $(0.001 \mathrm{~g} / 100 \mathrm{~g}$ dry weight of nonfermented mung bean and $0.134 \mathrm{~g} / 100 \mathrm{~g}$ dry weight of fermented mung bean) (result not shown) had also been reported as being an enhancer to the insulin-receptor tyrosine kinase activity in type II diabetic patients [21]. These free amino acids or more specifically lysine may contribute synergistically with GABA to regulate the blood glucose of the fermented mung beanextract treated diabetic mice.

Elevated serum lipid profile including cholesterol, TG, LDL with low HDL level is one of the pathogenesis of diabetes that also representing the risk factor for coronary heart disease [9]. In this study, alloxan-treated diabetic mice was observed with high serum cholesterol, TG, and LDL when compared with normal mice. Treatment with $M$. charantia, fermented and nonfermented mung bean extracts were able to reduce the risk factors for coronary heart disease by restoring the healthy lipid profile in the alloxan-induced diabetic mice. Other than a higher lipid profile, the serum of 
diabetic patient was also indicated with higher level of MDA and oxidative stress $[22,23]$. We have observed higher levels of MDA in untreated diabetic mice. Fermentation was able to improve the in vitro antioxidant and phenolic contents of mung bean [17]. This effect may contributed greatly to the reduction of the MDA level of the fermented mung bean extract ( $1000 \mathrm{mg} / \mathrm{kg}$ body weight) treated diabetic mice. Besides, our results also showed that fermented mung bean extract was able to reduce the nitric oxide (NO) level in the serum of the alloxan-induced diabetic mice in a dosage dependent manner. This result was similar with report of S. J. Lee et al. [24] where ethanolic extract of mung bean showed anti-inflammatory effect and reduced NO synthesis in a macrophage cell line. This effect may also be contributed by GABA which can suppress inflammation. Inflammation is one of the important features that contributed to $\beta$-cell death [25]. Thus, the significant reduction of NO by a high concentration of fermented mung bean extract may indirectly help to reduce the damage of $\beta$-cell.

In this study, fermented mung bean extract further improved the antihyperglycemic effect of nonfermented mung bean extract in both glucose and alloxan-induced hyperglycemic mice. This effect may be due to the improvement of the GABA and free amino acid contents through the fermentation process. Investigating on the details mechanism of fermented mung bean's antihyperglycemic effect are still on-going.

\section{Acknowledgments}

This study was supported by the e-Science Fund (Ministry of Agriculture, Malaysia). The authors would like to thanks Professor S. G. Tan for proof-reading of this paper.

\section{References}

[1] S. Rungseesantivanon, N. Thenchaisri, P. Ruangvejvorachai, and S. Patumraj, "Curcumin supplementation could improve diabetes-induced endothelial dysfunction associated with decreased vascular superoxide production and PKC inhibition," BMC Complementary and Alternative Medicine, vol. 10, article 57, 2010.

[2] D. Y. Kwon, J. W. Daily, H. J. Kim, and S. Park, "Antidiabetic effects of fermented soybean products on type 2 diabetes," Nutrition Research, vol. 30, no. 1, pp. 1-13, 2010.

[3] B. Kameswararao, M. M. Kesavulu, and C. Apparao, "Evaluation of antidiabetic effect of Momordica cymbalaria fruit in alloxan-diabetic rats," Fitoterapia, vol. 74, no. 1-2, pp. 7-13, 2003.

[4] M. L. Wheeler, "Nutrition management and physical activity as treatments for diabetes," Primary Care, vol. 26, no. 4, pp. 857-868, 1999.

[5] B. A. S. Reyes, N. D. Bautista, N. C. Tanquilut et al., "Antidiabetic potentials of Momordica charantia and andrographis paniculata and their effects on estrous cyclicity of alloxaninduced diabetic rats," Journal of Ethnopharmacology, vol. 105, no. 1-2, pp. 196-200, 2006.

[6] M. Lerer-Metzger, S. W. Rizkalla, J. Luo et al., "Effects of longterm low-glycaemic index starchy food on plasma glucose and lipid concentrations and adipose tissue cellularity in normal and diabetic rats," British Journal of Nutrition, vol. 75, no. 5, pp. 723-732, 1996.

[7] M. He, R. M. Van Dam, E. Rimm, F. B. Hu, and L. Qi, "Wholegrain, cereal fiber, bran, and germ intake and the risks of all-cause and cardiovascular disease-specific mortality among women with type 2 diabetes mellitus," Circulation, vol. 121, no. 20, pp. 2162-2168, 2010.

[8] J. C. Brand, S. Colagiuri, S. Crossman, A. Allen, D. C. K. Roberts, and A. S. Truswell, "Low-glycemic index foods improve long-term glycemic control in NIDDM," Diabetes Care, vol. 14, no. 2, pp. 95-101, 1991.

[9] Y. Yao, F. Chen, M. Wang, J. Wang, and G. Ren, "Antidiabetic activity of Mung bean extracts in diabetic KK-Ay mice," Journal of Agricultural and Food Chemistry, vol. 56, no. 19, pp. 8869-8873, 2008.

[10] A. O. Aderibigbe, T. S. Emudianughe, and B. A. S. Lawal, "Evaluation of the antidiabetic action of mangifera indica in mice," Phytotherapy Research, vol. 15, no. 5, pp. 456-458, 2001.

[11] W. Y. Ho, W. S. Liang, S. K. Yeap et al., "In vitro and in vivo antioxidant activity of vernonia amygdalina water extract," African Journal of Biotechnology, vol. 11, pp. 4090-4094, 2012.

[12] C. C. Shih, C. H. Lin, and W. L. Lin, "Effects of Momordica charantia on insulin resistance and visceral obesity in mice on high-fat diet," Diabetes Research and Clinical Practice, vol. 81, no. 2, pp. 134-143, 2008.

[13] H. Zhang, Y. Yi, D. Feng, Y. Wang, and S. Qin, "Hypoglycemic properties of oxovanadium (IV) coordination compounds with carboxymethyl-Carrageenan and carboxymethylchitosan in alloxan-induced diabetic mice," Evidence-Based Complementary and Alternative Medicine, vol. 2011, Article ID 691067, 7 pages, 2011.

[14] H. Hosseinzadeh, M. Ramezani, and A. R. Danaei, "Antihyperglycaemic effect and acute toxicity of securigera securidaca L. seed extracts in mice," Phytotherapy Research, vol. 16, no. 8, pp. 745-747, 2002.

[15] J. Brand-Miller, S. Hayne, P. Petocz, and S. Colagiuri, "Lowglycemic index diets in the management of diabetes: a metaanalysis of randomized controlled trials," Diabetes Care, vol. 26, no. 8, pp. 2261-2267, 2003.

[16] D. Y. Kwon, J. S. Jang, S. M. Hong et al., "Long-term consumption of fermented soybean-derived chungkookjang enhances insulinotropic action unlike soybeans in 90\% pancreatectomized diabetic rats," European Journal of Nutrition, vol. 46, no. 1, pp. 44-52, 2007.

[17] R. Randhir and K. Shetty, "Mung beans processed by solidstate bioconversion improves phenolic content and functionality relevant for diabetes and ulcer management," Innovative Food Science and Emerging Technologies, vol. 8, no. 2, pp. 197204, 2007.

[18] N. Soltani, H. Qiu, M. Aleksic et al., "GABA exerts protective and regenerative effects on islet beta cells and reverses diabetes," Proceedings of the National Academy of Sciences of the United States of America, vol. 108, no. 28, pp. 11692-11697, 2011.

[19] J. Tian, H. N. Dang, J. Yong et al., "Oral treatment with $\gamma$-aminobutyric acid improves glucose tolerance and insulin sensitivity by inhibiting inflammation in high fat diet-fed mice," PLoS ONE, vol. 6, no. 9, Article ID e25338, 2011.

[20] K. N. Sulochana, S. Lakshimi, R. Punitham et al., "Effect of oral supplementation of free amino acids in type 2 diabetic patients-a pilot clinical trial," Medical Science Monitor, vol. 8, no. 3, pp. CR131-CR137, 2002. 
[21] K. N. Sulochana, M. Rajesh, and S. Ramakrishnan, "Insulin receptor tyrosine kinase activity in monocytes of type 2 diabetes mellitus patients receiving oral L-lysine," Indian Journal of Biochemistry and Biophysics, vol. 38, no. 5, pp. 331334, 2001.

[22] F. N. Ahmed, F. N. Naqvi, and F. Shafiq, "Lipid peroxidation and serum antioxidant enzymes in patients with type 2 diabetes mellitus," Annals of the New York Academy of Sciences, vol. 1084, pp. 481-489, 2006.

[23] R. K. Padalkar, A. V. Shinde, and S. M. Patil, "Lipid profile, serum malondialdehyde, superoxide dismutase in chronic kidney diseases and type 2 diabetes mellitus," Biomedical Research, vol. 23, pp. 207-210, 2012.

[24] S. J. Lee, J. H. Lee, H. H. Lee et al., "Effect of mung bean ethanol extract on pro-inflammtory cytokines in LPS stimulated macrophages," Food Science and Biotechnology, vol. 20, no. 2, pp. 519-524, 2011.

[25] S. E. Choi, K. M. Choi, I. H. Yoon et al., "IL-6 protects pancreatic islet beta cells from pro-inflammatory cytokinesinduced cell death and functional impairment in vitro and in vivo," Transplant Immunology, vol. 13, no. 1, pp. 43-53, 2004. 

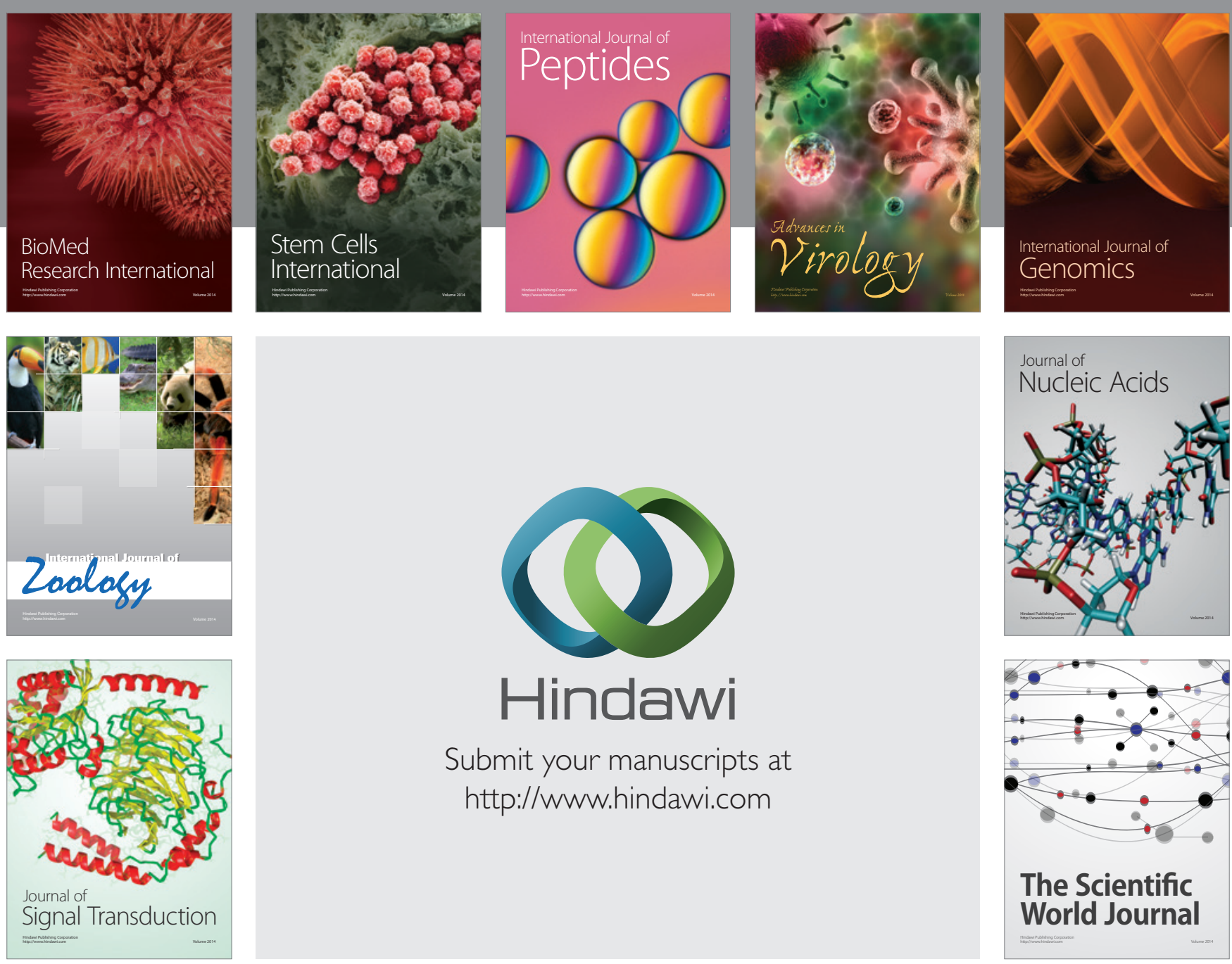

Submit your manuscripts at

http://www.hindawi.com
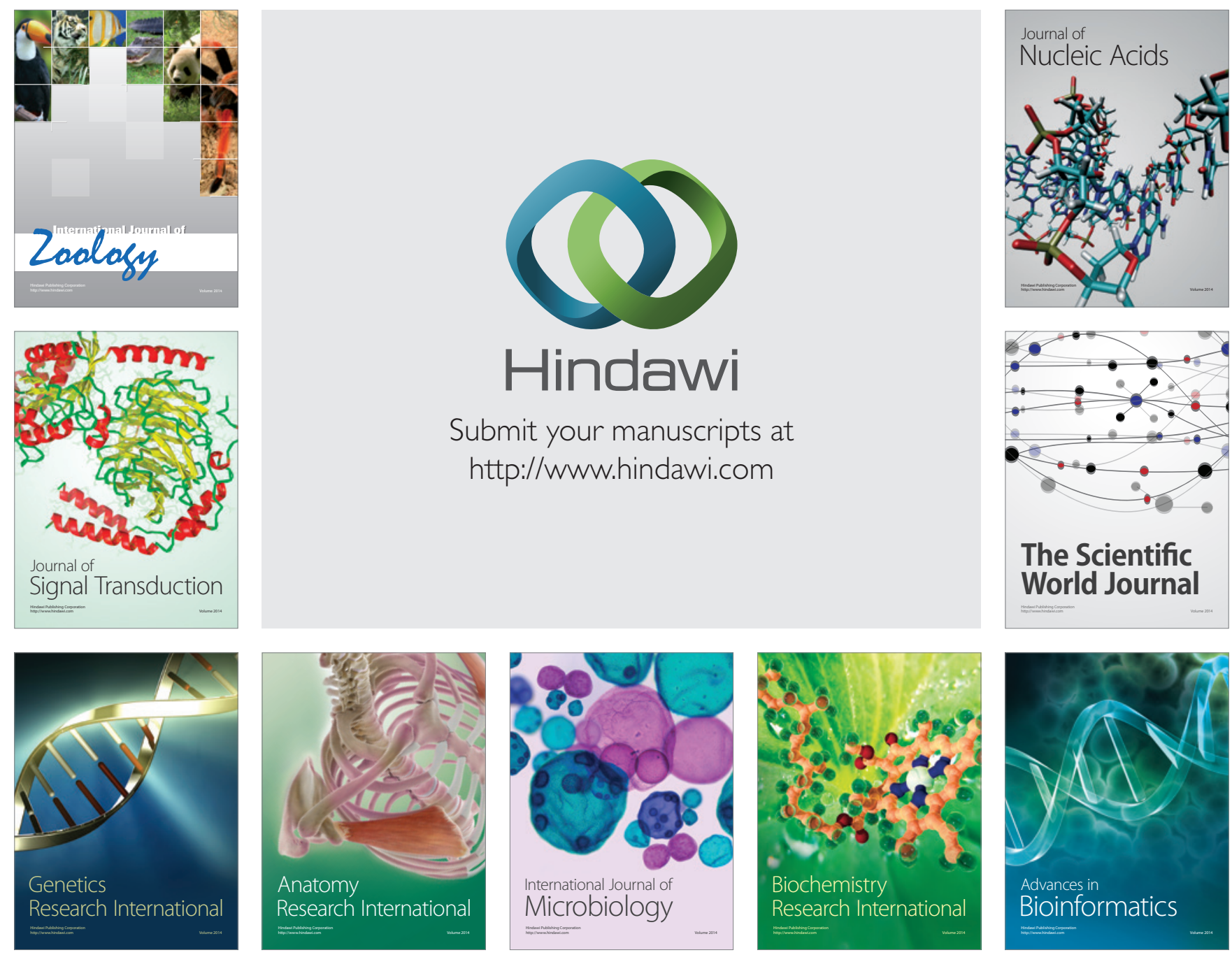

The Scientific World Journal
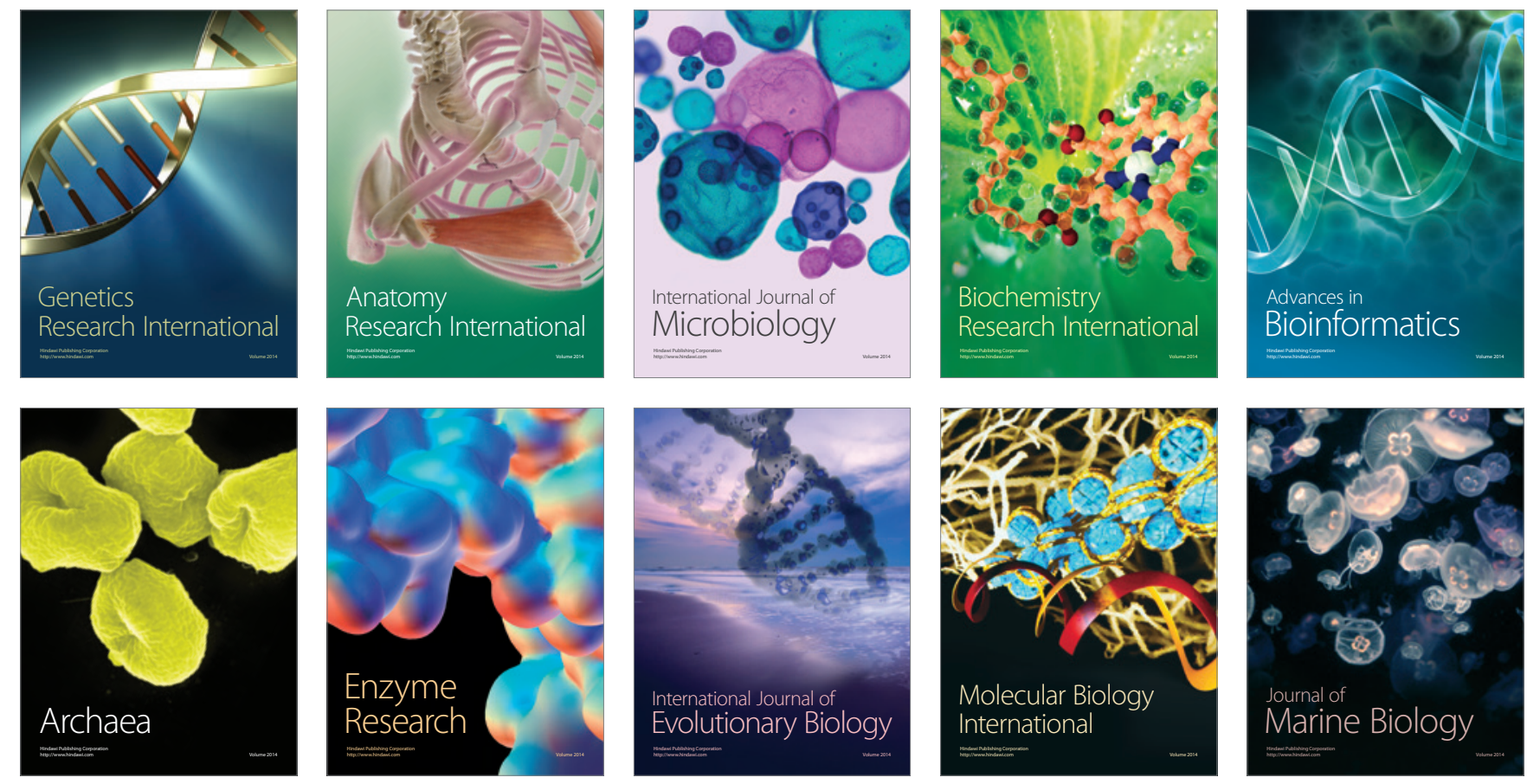